\title{
Evidence that DNA fragmentation in apoptosis is initiated and propagated by single-strand breaks
}

\author{
P. Roy Walker, Julie LeBlanc and Marianna Sikorska \\ 1 Apoptosis Research Group, Institute for Biological Sciences, National \\ Research Council of Canada, Ottawa, Ontario, Canada K1A OR6 \\ 2 corresponding author: Roy Walker, Ph. D., Apoptosis Research Group, \\ Institute for Biological Sciences, National Research Council, Bldg. M54, \\ Montreal Rd., Ottawa, Ont. Canada K1A OR6. tel: (613) 993-2892, \\ fax: (613) 990 7963; email: roy.walker@nrc.ca
}

Received 14.10.96; revised 24.2.97; accepted 21.4.97

Edited by L. Fesus

\begin{abstract}
Apoptosis is characterised by the degradation of DNA into a specific pattern of high and low molecular weight fragments seen on agarose gels as a distribution of sizes between $50-$ $300 \mathrm{~kb}$ and sometimes, but not always, a ladder of smaller oligonucleosomal fragments. Using a 2D pulsed fieldconventional agarose gel electrophoresis technique, where the second dimension is run under either normal or denaturing conditions, we show that single-strand breaks are introduced into DNA at the initial stages of fragmentation. Using singlestrand specific nuclease probes we further show that the complete fragmentation pattern, including release of small oligonucleosomal fragments can also be generated by a single-strand endonuclease. Three classes of sites where single-strand breaks accumulate were identified. The initial breaks produce a distribution of fragment sizes $(50 \mathrm{~kb}$ to $>1 \mathrm{Mb}$ ) similar to those generated by Topoisomerase II inhibitors suggesting that cleavage may commence at sites of attachment of DNA to the nuclear matrix. A second class of rare sites is also cut further reducing the size distribution of the fragments to $50-300 \mathrm{~kb}$. Thirdly, single-strand breaks accumulate at the linker region between nucleosomes eventually causing double-strand scissions which release oligonucleosomes. These observations further define the properties of the endonuclease responsible for DNA fragmentation in apoptosis.
\end{abstract}

Keywords: endonuclease, thymocyte, oligonucleosome, matrix

Abbreviations: CAGE, conventional agarose gel electrophoresis; DCl, dichloroisocoumarin; dsb, double-strand break; HMW, high molecular weight; kb, kilobasepairs; PFGE, pulsed field gel electrophoresis; ssb, single-strand break; Topo I (II), topoisomerase I (II)

\section{Introduction}

DNA breakdown in apoptosis produces a characteristic pattern of high and low molecular weight fragments (Walker et al, 1995; Walker and Sikorska, 1994; Sun and Cohen, 1994; Zhivotovsky et al, 1994). The $>50 \mathrm{~kb}$ high molecular weight (HMW) fragments are thought to arise from the cleavage of DNA domains at matrix attachment regions (MARs, Walker and Sikorska, 1994; Lagarkova et al, 1995) whereas the smaller fragments (the DNA ladder) arise from endonucleolytic activity at the linker regions of oligonucleosomal fragments within domains (Wyllie, 1980). There is considerable variability in the extent to which different cell types fragment their DNA and in any given cell type fragmentation proceeds to a specific point, regardless of cell death stimulus, but is never complete (i.e. total degradation all the way to mononucleosomes or nucleotides) in any cell type. Thus, MCF-7 breast cancer cells produce only HMW fragments whereas thymocyte primary cultures and many lymphocyte cell lines produce predominantly DNA ladders (Walker et al, 1995). Since in the latter cell types oligonucleosomal, but not HMW, fragmentation can be prevented by incubating the cells with serine protease inhibitors (Weaver et al, 1994) or zinc (Sun and Cohen, 1994) it has been assumed that DNA fragmentation proceeds in at least two stages, generating first HMW DNA which is subsequently degraded in some, but not all cells, to smaller oligonucleosomal fragments. Experiments with isolated nuclei have reinforced this view by defining specific ionic requirements for each of the stages of degradation. In general, HMW fragments are produced when nuclei are incubated in buffers containing $\mathrm{Mg}^{2+}$ as the only divalent cation, whereas oligonucleosomal fragments are produced when both $\mathrm{Mg}^{2+}$ and $\mathrm{Ca}^{2+}$ are present in the digestion buffer. We have ascribed these two sets of properties to one enzyme activity (Walker et al, 1995), although it has been suggested that two different enzymes may be involved (Sun and Cohen, 1994). The true relationship between these two enzymes or activities and, indeed, between the two stages of fragmentation are not understood.

The pattern of DNA degradation seen in apoptosis is a consequence of the interaction of DNA with proteins in chromatin such that some sites along the DNA molecule are protected more than others from endonucleolytic attack. It is also possible that sequence-determined structural alterations in DNA conformation are targets of endonucleases (Herrmann et al, 1996). Thus, nuclear matrixattached DNA is very sensitive to endonucleolytic attack by both endogenous and exogenous nucleases because of the highly modified or unpaired DNA structures at these sites (Probst and Herzog, 1985; Luderus et al, 1994). Indeed, in some lymphocytes such sites appear to be extremely fragile and may harbour single-strand breaks 
(Szabo and Bacso, 1996). The DNA within domains is more protected by virtue of its interaction with core histones and histone $\mathrm{H} 1$. Evidence that the internucleosomal linker region becomes somehow modified, increasing its nuclease sensitivity, prior to cleavage was provided by Tomei et al (1993) who showed that the larger fragments of DNA from apoptotic $\mathrm{C} 3 \mathrm{H} / 10 \mathrm{~T}^{1} / 2$ cells (which do not normally degrade their DNA to small fragments) appeared to contain a modification in the linker region that was sensitive to alkali and to S1 nuclease. In another study, Pietsch et al (1993) analyzed the small oligonucleosomal fragments generated at the completion of DNA degradation in apoptotic thymocytes and showed that numerous singlestrand breaks (ssb) were present in the linker regions. Furthermore, cytotoxic $T$ cells induce the formation of ssb into the DNA of target cells during killing (Gromowski et al, 1986; Ucker et al, 1992) and the destruction of DNA in lens fibre cells during development (Appleby and Modak, 1977; Arruti et al, 1995), two processes that are similar if not identical to apoptosis, also involves the formation of ssb in the linker regions of chromatin. Although it is evident from these studies that changes in chromatin structure and/or ssb formation play a role in the later stages of DNA fragmentation in apoptosis their roles in the two stages of breakdown have not been studied.

Using a variety of probes of chromatin structure, coupled with 2D pulsed field-conventional agarose gel electrophoresis, we have examined the role of $s s b$ formation in the complete process of DNA fragmentation in apoptotic thymocytes and during cation-induced DNA fragmentation in permeabilised cells with particular emphasis on the early stages. The data supports a model in which DNA fragmentation in apoptosis is catalyzed, in its entirety, by a single strand specific endonuclease cleaving DNA at both unpaired regions between large domains of chromatin, which are believed to be attached to the nuclear matrix, and in the linker regions of nucleosome-organised DNA within domains. The various patterns of DNA fragmentation seen in different cell types and in different types of cell killing (apoptosis, cytolysis, etc.) can be explained by a common mechanism that progresses to varying extents.

\section{Results}

\section{Electrophoresis separations}

The conditions chosen for PFGE in these experiments permitted the ordered separation of fragments ranging from $100 \mathrm{bp}$ to approximately $1 \mathrm{Mb}$ on the same gel. Figure $1 \mathrm{~A}$ shows a typical run with various size markers spanning the range of resolvable sizes. For accurate sizing of HMW DNA fragments and identification of peaks during digestions it is essential to have a PFGE separation that is as linear as possible and contains no zones of compression. The standard curves generated in Figure 1B, from digitised scans of the lanes in Figure $1 \mathrm{~A}$ showed that the separation was relatively linear from about $1.1 \mathrm{Mb}$ to $30-50 \mathrm{~kb}$ (upper panel). The larger yeast chromosomes $(>1.64 \mathrm{Mb})$ did not enter the gel under these conditions. Fragments $<20-$
$30 \mathrm{~kb}$ migrate essentially as they would under static field conditions producing a well-resolved logarithmic separation (Figure 1B, lower panel; correlation coefficient for logarithmic curve fitting $=0.93$ ). Fragments were also ordered and well-resolved in the critical transition region between the linear and logarithmic parts of the separation. By using the same programmed ROM card the resolution of the separation is maintained for every run over a long period of time. A CCD camera was used to acquire images of the ethidium bromide-stained gels to ensure a linear response to light intensity (Ribeiro et al, 1989). Exposures were selected so that the maximum intensity of the CCD array was not exceeded.

A two dimensional technique, based on experiments described by Appleby and Modak (1977) and Muel et al (1986), using PFGE in the first dimension and either conventional or denaturing agarose gel electrophoresis in the second dimension was developed to detect the presence of ssb in both HMW and oligonucleosomal DNA. This was achieved by running two samples on the PFGE gel, one loaded in the left lane and one in the centre lane. After the PFGE separation, the gel was rotated and prepared for the second dimension as described in Materials and Methods. Depending on the second dimension conditions, the DNA fragments either remain double-stranded in the case of a PFGE-CAGE separation, or become single-stranded under the PFGE-denaturing conditions. If no ssb were formed during apoptosis the two profiles would be identical, but if ssb were produced some smaller fragments would be detected under denaturing conditions.
A

1234

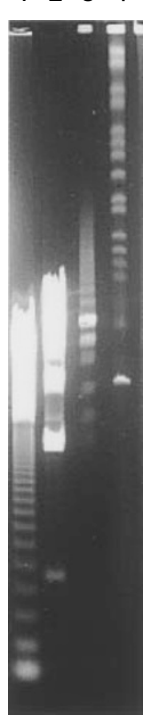

B
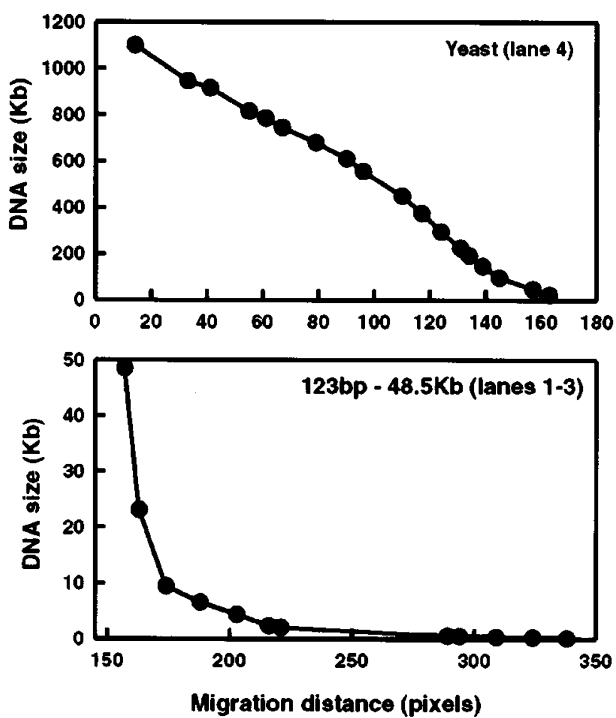

Figure 1 Separation range and resolution of the standard PFGE conditions. (A) DNA size markers were resolved using the standard PFGE conditions: lane 1, 123 bp ladder; lane 2, Hindlll digest of lambda DNA; lane 3, low range DNA markers; lane 4, Yeast chromosomes. (B) standard curves generated by data analysis of a digitised image of the lanes in (A). 


\section{Single-strand breaks are formed in HMW DNA during apoptosis}

To detect the existence of single-stranded breaks in HMW DNA fragments from apoptotic cells embedded thymocytes were incubated for $4 \mathrm{~h}$ with dex, duplicate agarose plugs were deproteinised and the DNA in each plug subjected to a 1st dimension separation by PFGE (Figure 2, top lane). One gel was then subject to a 2 nd dimension separation by CAGE (upper panel) whereas the other was run under denaturing conditions (centre panel). The first dimension PFGE separation gave the typical profile of $\sim 50 \mathrm{~kb}$ and oligonucleosomal DNA fragments found in apoptotic thymocytes. Fragments $50 \mathrm{~kb}$ or greater migrated poorly in the 2nd dimension of CAGE whereas the smaller fragments entered the gel producing a logarithmic 2D separation profile. Under denaturing conditions a similar overall profile was obtained since some of the fragments were the same size (centre panel). The two gels do not overlap precisely because of the very different conditions required to attain a separation. However, it is clear that under denaturing conditions a large number of smaller fragments migrated underneath the intact fragments. This was particularly noticeable under the HMW $(\sim 50 \mathrm{~kb})$ fragments showing that a large number of ssb were present in this DNA. The single-stranded fragments ranged in size from 200 bases to approximately $50 \mathrm{~kb}$. Significantly, some of the DNA that remained in the wells during PFGE $(>2-3 \mathrm{Mb})$ entered the gel in the second dimension under denaturing conditions indicating that many ssb were also accumulating in this very HMW DNA during the initial stages of apoptotic DNA fragmentation. To eliminate the possibility that the manipulations themselves were generating ssbs in the DNA, a sample of control cell DNA from the same number of cells, to ensure equal loading, was taken through the same procedures and subjected to 2D PFGE-denaturing gel electrophoresis (lower panel). All the DNA remained in the well showing that there were neither dsb nor ssb introduced as a result of the manipulations.

The oligonucleosomal ladder of DNA fragments seen in many apoptotic cells arises from the scission of both strands at the linker regions between histones. To test whether ssb accumulated at these sites in HMW DNA fragments of apoptotic cells, prior to being converted to $\mathrm{dsb}$, we incubated embedded thymocytes for $4 \mathrm{~h}$ with dex (Figure $3 A$, lanes 4-6). Following the incubations, plug slices were cut in triplicate, the DNA deproteinised and one slice was not further treated (lanes 4 and 7) whereas the second and third slices were incubated in buffer containing S1 nuclease for $1 \mathrm{~h}$ (lanes 5 and 8 ) or $2 \mathrm{~h}$ (lanes 6 and 9), respectively. It is important to emphasise that in this and subsequent experiments $S 1$ nuclease treatment was on deproteinised DNA, not DNA in whole nuclei. All the slices were then loaded on a gel and subject to PFGE. Cells incubated with dex (lane 4) showed the typical pattern of apoptotic DNA fragments described above. A scan of pixel intensities of lane 4 from the digital image of the gel showed that most of the DNA was oligonucleosomal and low molecular weight (i.e. $200 \mathrm{bp}-30 \mathrm{~kb}$ ) with some residual fragments of $30-50 \mathrm{~kb}$ (Figure $3 \mathrm{~B}$ ). S1 nuclease treatment of this DNA produced two effects. It further
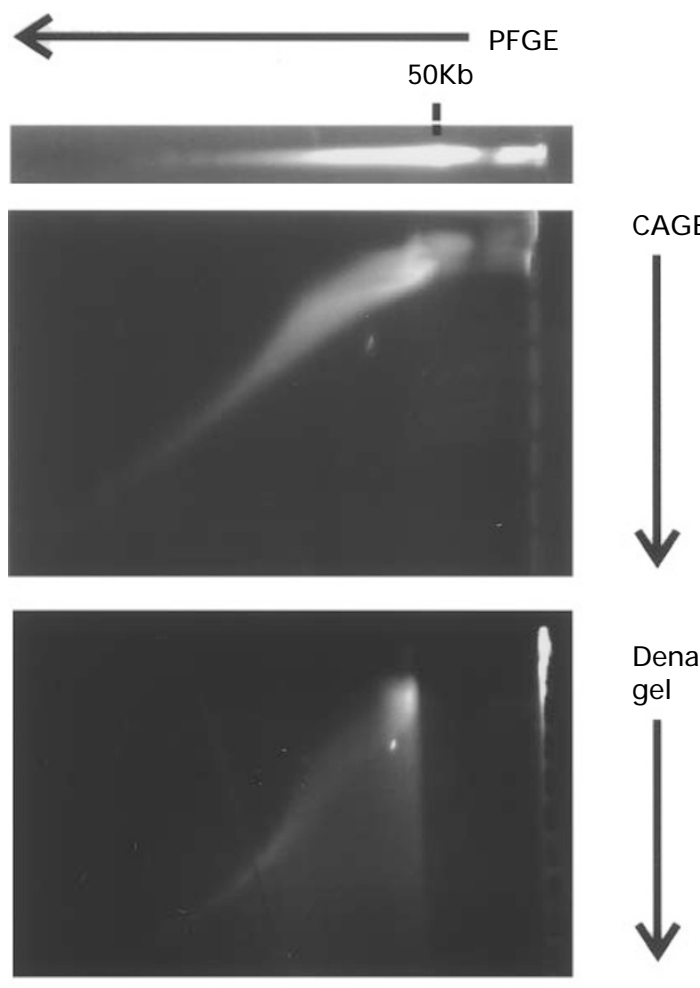

Denaturing gel

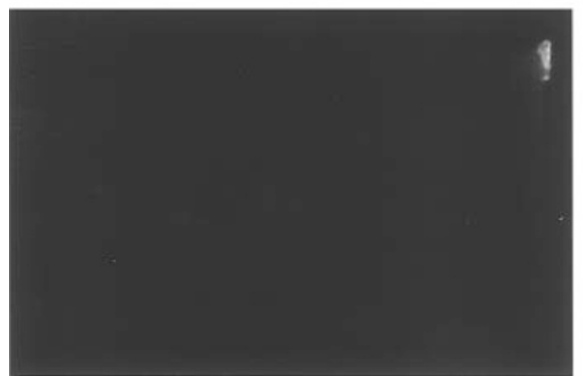

Denaturing gel (control)

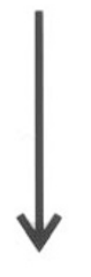

Figure 2 2D gel electrophoresis of DNA from control and apoptotic cells Embedded thymocytes were treated for $4 \mathrm{~h}$ with dex and the deproteinised DNA subjected to a first dimension separation by PFGE (top lane) and then subjected to a second dimension separation of either CAGE (upper panel) or denaturing electrophoresis (centre panel). The integrity of control cell DNA subjected to the same PFGE-denaturing 2D gel electrophoresis separation is shown in the lower panel.

reduced the size of the ladder (Figure 3A, lanes 5 and 6) confirming the observation of Pietsch et al (1993) that ssb exist at linker regions in these fragments. $\mathrm{S} 1$ also generated some HMW fragments, presumably from the cells with DNA in which ssb were accumulating. Some large fragments of DNA were also released by $\mathrm{S} 1$ nuclease from plugs prepared from cells incubated without dex (lanes 2 and 3 compared to control DNA, lane 1 ).

In a parallel experiment, cells were incubated with dex and the protease inhibitor dichloroisocoumarin $(\mathrm{DCl})$ at $50 \mu \mathrm{M}$ (lanes 7-9). The serine protease inhibitor $\mathrm{DCl}$ has been shown to prevent the formation of fragments of less than $50 \mathrm{~kb}$ during apoptosis (Weaver et al, 1994). As expected, no oligonucleosomal fragments were produced and most of the DNA was in the size range of $50 \mathrm{~Kb}-1 \mathrm{Mb}$ 
A

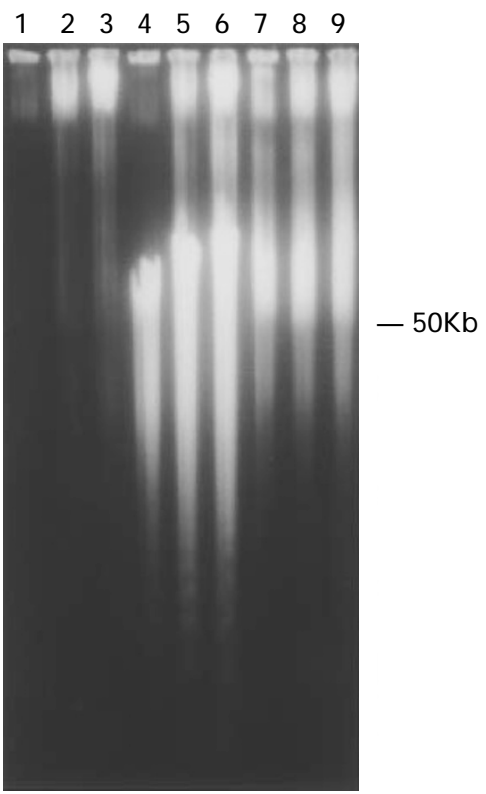

B

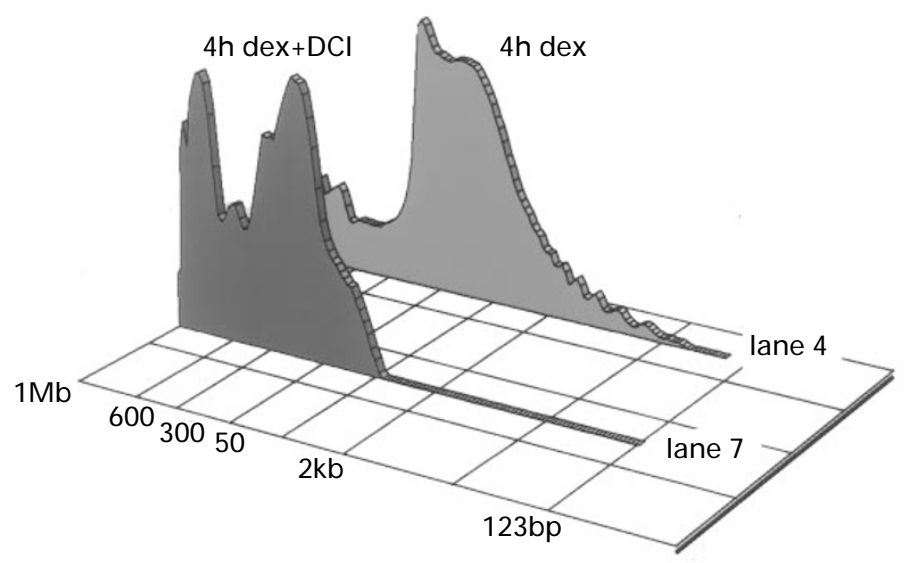

Figure 3 PFGE analysis of DNA from embedded control cells (lanes 1-3) or cells treated for $4 \mathrm{~h}$ with dex (lanes $4-6$ ) or dex and $50 \mu \mathrm{M} \mathrm{DCl}$ (lanes $7-9$ ). After the incubations the DNA was either not further digested (lanes $1,4,7$ ) or digested for $1 \mathrm{~h}$ (lanes $2,5,8$ ) or $2 \mathrm{~h}$ (lanes $3,6,9$ ) with $\mathrm{S} 1 \mathrm{huclease}$. The position of the $50 \mathrm{~kb}$ DNA size marker is indicated at the right of the gel. Scans of lanes 4 and 7 from the digital image are shown in $\mathbf{B}$.

(lane 7, scan shown in Figure 3B). Distinct peaks at 50, 300 and $600 \mathrm{~kb}$ were evident in the profile. Subsequent S1 nuclease treatment of these samples did not further reduce the average size of the fragments indicating that there was no accumulation of ssb within the linker regions in the absence of proteolysis (lanes 8 and 9).

\section{Size distribution of DNA fragments liberated by VM26 and S1 nuclease}

When cells are incubated with the topoisomerase II (topo II) inhibitor VM26 and rapidly deproteinised the DNA is cleaved at those MAR sites at which topo II is bound (Gromova et al, $1995 \mathrm{a}, \mathrm{b})$. We established the pattern and distribution of such fragments in thymocytes, either in suspension or embedded in agarose, by treating with VM26 for $30^{\prime}$ followed by rapid denaturation, proteolysis and PFGE (Figure 4A). Since Topoll inhibitors can induce apoptosis the incubation was kept to $30^{\prime}$ to avoid the activation of endonucleases (Walker et al, 1991). Cells incubated for $30^{\prime}$ in the absence of VM26 did not accumulate any dsb (lane 2) over and above the small number of dsb, producing some fragments of $>600 \mathrm{~kb}$, that are often seen in these primary cultures (lane 1, zero time). A characteristic, highly reproducible pattern of fragment sizes ranging from $50 \mathrm{~kb}$ to approximately $1 \mathrm{Mb}$ was obtained in cells incubated for $30^{\prime}$ with VM26 (lane 3, scan shown in Figure 4B). Pronounced peaks were obtained at 50, 300 and $600 \mathrm{~kb}$ that were well within the linear separation range of the gel eliminating the possibility that they could be due to compression artifacts (Gromova et al, 1995a). This pattern was remarkably similar to that observed during the initial stages of fragmentation in apoptosis (see Figure $3 \mathrm{~b}$ ) and during the early stages of digestion with endogenous nucleases (see Figure 5B, lane 2). Only a small fraction of the DNA remained in the wells. The datas shown is for embedded thymocytes but equivalent results were obtained when VM26 was added to cell suspensions prior to embedding (data not shown). Prolonged incubation of the cells with VM26 did not further reduce the size distribution of the fragments (data not shown).

A similar distribution of fragment sizes was obtained by incubating deproteinised control cell DNA with S1 nuclease (lane 5, scan shown in Figure 4B). Although less pronounced, peaks at 50,300 and $600 \mathrm{~kb}$ were also evident. Similar results were obtained following digestions with Mung Bean nuclease (data not shown). The DNA in deproteinised embedded cells has been shown to remain intact (see Figure 2, lower panel), retain its supercoiled structure and contains regions of either unpaired or altered strand conformation (Probst and Herzog, 1985) that are sensitive to single-strand specific nucleases, such as S1 and Mung bean nuclease (Probst and Herzog, 1985; Luderus et al, 1994). The absence of nicks in this DNA (Figure 2, lower panel) eliminated the possibility that the S1 nuclease sensitivity could have been due to the presence of artefactually-induced ssb.

To eliminate the possibility that the ssb were being introduced by topoisomerase I (topo I) similar experiments were carried out with camptothecin, a Topo I-inhibitor (lanes 4 and 6). There was no fragmentation of DNA in either suspension or embedded cells. Furthermore, the drug did not prevent the subsequent degradation by $\mathrm{S} 1$ nuclease.

These results indicate that supercoiled, intact DNA contains sites that are either unpaired or in an altered conformation. The sites are not randomly distributed and 
A

123456

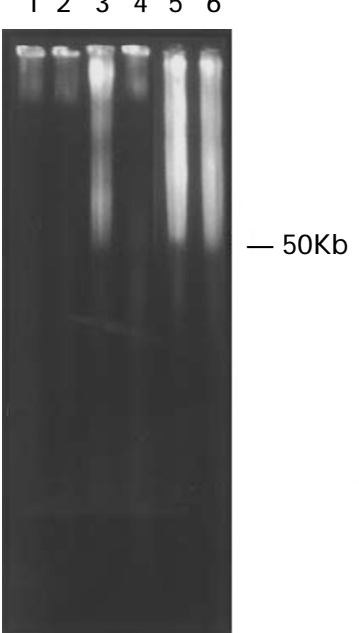

B

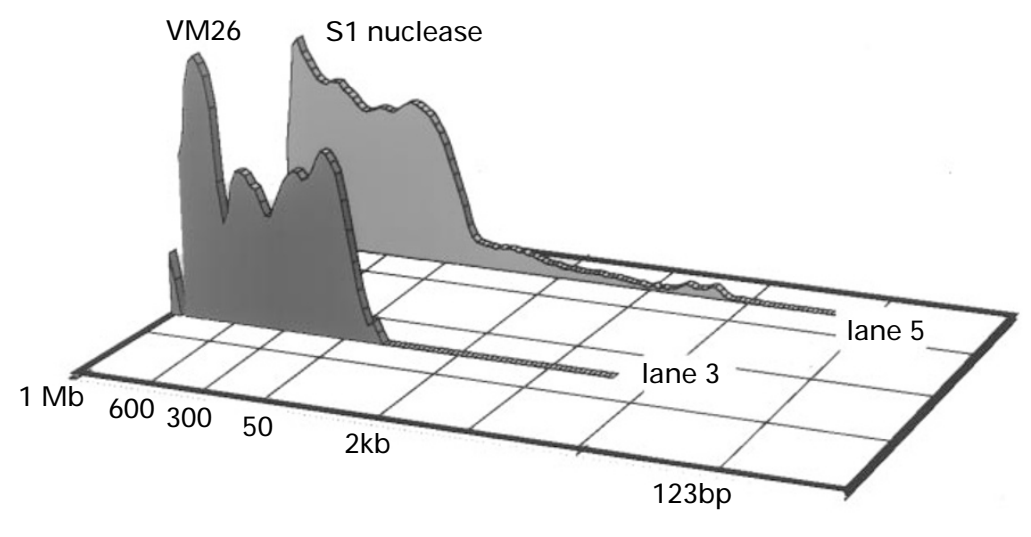

Figure 4 Distribution of DNA fragment sizes from cells incubated for 30' in the absence (Panel A, lane 2) or presence of $10 \mu \mathrm{M}$ VM26 (lane 3 ) or camptothecin at $100 \mu \mathrm{M}$ (lanes 4, 6). Lanes 1 and 5 contain DNA from untreated cells. Following the incubations the deproteinised DNA was either not further digested (lanes $1-4)$ or digested for $1 \mathrm{~h}$ with S1 nuclease (lanes 5,6 ). (B) scan of lanes 3 (cells treated for 30' with $10 \mu \mathrm{M}$ VM26) and 5 (control cell DNA digested with S1 nuclease) from the digital image of $\mathbf{A}$. The positions of representative size markers are indicated.

digestion of this DNA with nucleases that can detect these regions generates a characteristic distribution of fragment sizes. A similar distribution of fragment sizes is generated by cleaving nuclear DNA with the topoisomerase II inhibitor, VM26, suggesting that topoisomerase II (but not topoisomerase I) interacts with chromatin at these sites of altered conformation.

\section{Ssb formation during DNA fragmentation by endogenous nucleases in permeabilised cells}

For these experiments, thymocytes were embedded in agarose and incubated with various cations in a permeabilisation buffer containing $0.5 \%$ Triton $\mathrm{X} 100$ (similar results were obtained with $0.1-0.5 \%$ detergent). NP40 detergent was not used because of high levels of DNA degrading activity (presumably oxidants) in some batches. The plugs were incubated, in duplicate, with $\mathrm{Mg}^{2+}$ and $\mathrm{Ca}^{2+}$ for the times indicated and then rapidly deproteinised. One of the duplicates was subsequently digested with S1 nuclease and both were loaded directly onto the gels, thereby minimising manipulations on the DNA. Following the run, the ethidiumstained gel was digitised and scans of the distribution of fragment sizes at each timepoint ( \pm S1 nuclease) are shown in Figure 5B. During the earliest stages of DNA digestion (5') in the presence of $\mathrm{Ca}^{2+}$ and $\mathrm{Mg}^{2+}$, at neutral $\mathrm{pH}$, a $\mathrm{HMW}$ distribution of fragments similar to those seen with VM26 or S1 nuclease was observed (Figure 5A, lanes 1-4). Further incubation lead to the conversion of the entire genome to fragments of $50-300 \mathrm{~kb}$ before any oligonucleosomal ladder appeared (lane 5). Eventually, these fragments were degraded with the release of oligonucleosomal fragments (lane 6). At all time points, subsequent incubation of either the control DNA or the incubated and deproteinised plugs with S1 nuclease further reduced the size distribution of the DNA fragments, producing the same pattern of oligonucleosomal fragments observed in apoptotic cells (lanes 7-12). Analysis of the scans (Figure 5B) revealed that, during digestion, S1 nuclease-sensitive sites were accumulating in DNA prior to their conversion to dsb. For example, the distribution of fragment sizes seen in the $5^{\prime}$ sample digested with $\mathrm{S} 1$ nuclease was similar to that seen after $15^{\prime}$ of incubation with $\mathrm{Ca}^{2+}$ and $\mathrm{Mg}^{2+}$ (Figure 6, centre panel). Similarly, the pattern seen at 30' followed by $\mathrm{S} 1$ nuclease digestion is similar to that eventually seen at $60^{\prime}$ (lower panel). The upper panel in Figure 6 confirms that at the earliest stages of endogenous digestion $\left(5^{\prime}\right)$ the size distribution of fragments produced is similar to that of control DNA digested with S1 nuclease suggesting that, indeed, these sites are coincident. Mung bean nuclease produced similar results to $\mathrm{S} 1$ nuclease (Figure 5C, lanes 9-12, cf. lanes 5-7). When Bal 31 was used to digest deproteinised DNA in plugs from control thymocytes (0 time cells) it produced a similar result to $S 1$ and Mung bean nuclease (lane 13). However, although it further reduced the size distribution of incubated samples, there was no oligonucleosomal pattern (lanes 14-16). Thus Bal 31 was not able to detect any specific structural alteration in the linker region and was not able to recognise the ssb. These results indicated that a substantial number of ssb were accumulating in the linker regions of large fragments prior to their conversion to dsb.

\section{Alterations in linker DNA helical twist inhibit internucleosomal DNA cleavage during apoptosis}

Since $\mathrm{S} 1$ nuclease can produce a dsb by either cleaving adjacent to a preexisting ssb or by recognising unpaired single-strand or structurally altered regions of DNA we tried to establish whether there were any structural alterations in the linker region DNA during apoptosis. There is recent evidence that DNA fragmentation involves sequences that have the capability to form bent DNA (Herrmann et al, 1996). Such a 
A

$122034556 \quad 7 \quad 89101112131415$

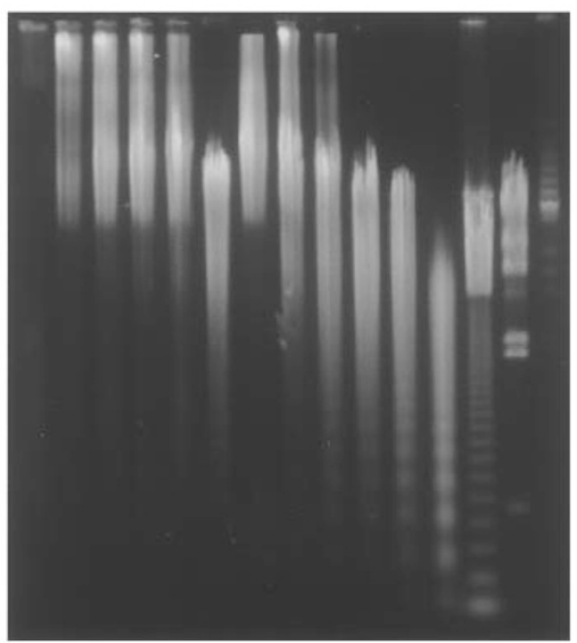

C

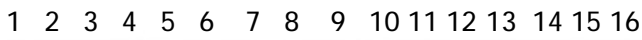

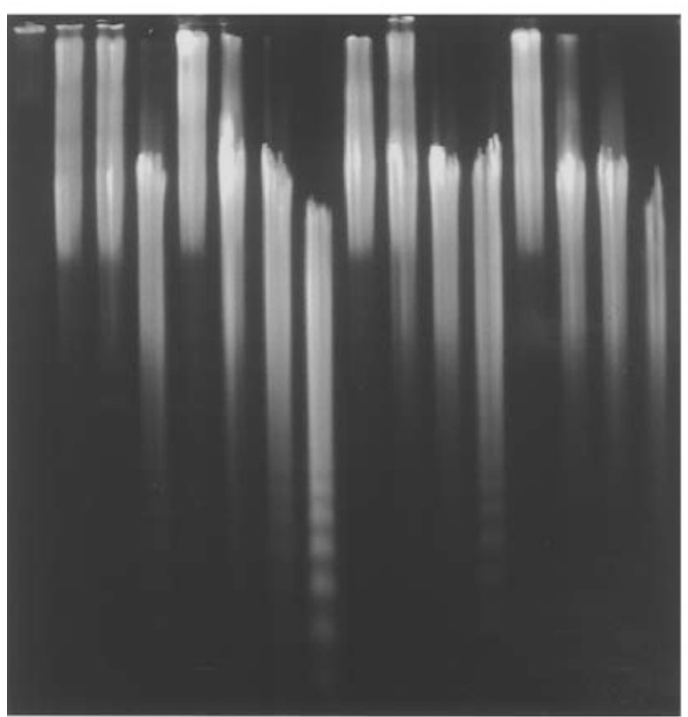

B
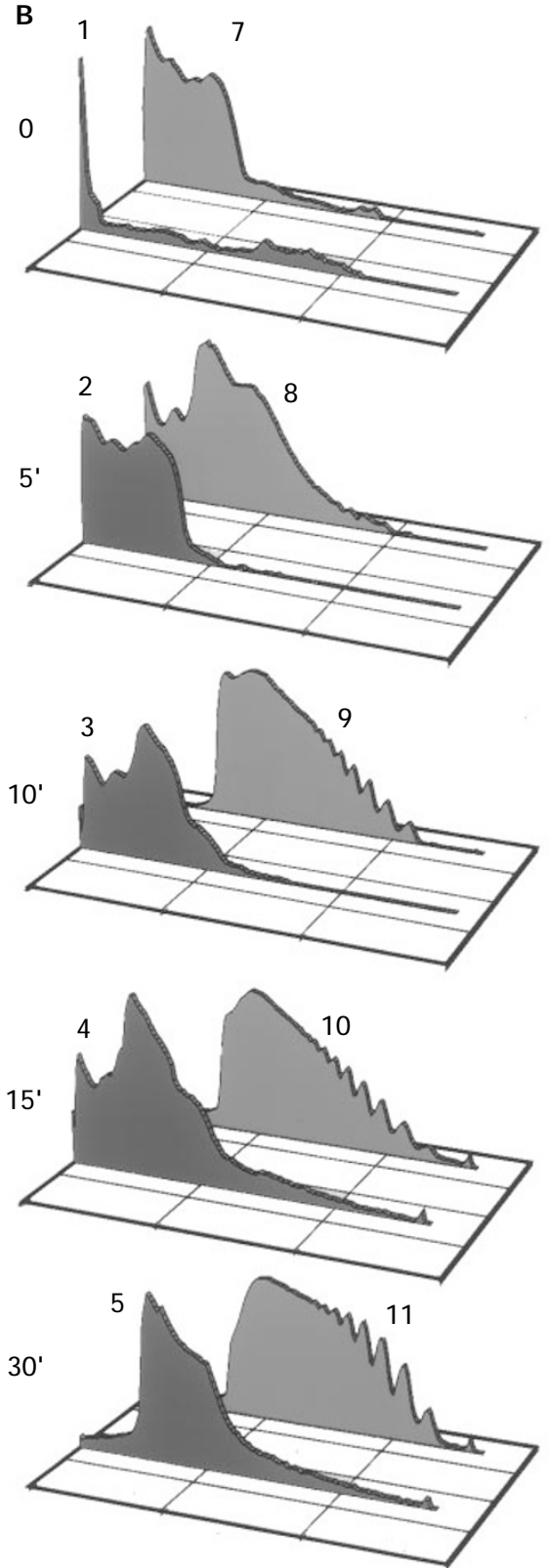

6

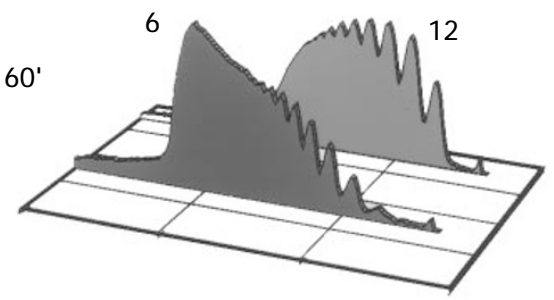

Figure 5 DNA fragmentation in embedded permeabilised normal cells. (A) cells were incubated in the presence of $2 \mathrm{mM} \mathrm{Mg}^{2+}$ and $1 \mathrm{mM} \mathrm{Ca}^{2+}$ for $0,5^{\prime}, 10^{\prime}, 15^{\prime}, 30^{\prime}$ or $60^{\prime}$ (lanes 1-6, 7-12). The plugs were deproteinised and then either not further treated (lanes 1-6) or incubated with S1 nuclease (lanes 7-12) prior to PFGE. Lane 13, 123 bp ladder, lane 14 HindllI digestion of Lambda DNA, lane 15, low range HMW markers. (B) scans of the samples at each time point \pm S1 nuclease digestion. For each image, the scan in the foreground is without $\mathrm{S} 1$ nuclease digestion and the scan in the background is the corresponding sample digested with $\mathrm{S} 1$ nuclease. The digestion time and lane assignments are indicated. (C) Embedded cells were incubated with $2 \mathrm{mM} \mathrm{Mg}^{2+}$ and $1 \mathrm{mM} \mathrm{Ca}^{2+}$ for $0,10^{\prime}, 15^{\prime}$ or $30^{\prime}$, deproteinised and plug slices subject to either no further treatment (lanes 1-4) or a secondary digestion with S1 nuclease (lanes 5-8), Mung Bean nuclease (lanes 9-12) or Bal 31 enzyme (lanes 13-16) as described in Materials and Methods followed by PFGE. 
conformational change may unwind the linker DNA and allow ss-specific nucleases to gain access to the DNA. To achieve this, embedded thymocytes were incubated for $2 \mathrm{~h}$ in the presence of dex and 0,1 or $4 \mathrm{mg} / \mathrm{ml}$ of chloroquine diphosphate (Figure 7A, lanes 2-4). Chloroquine, which has been shown to alter or prevent changes in linker DNA helical twist, inhibited the production of fragments of less than $50 \mathrm{~kb}$, and may have slowed, but did not prevent, the earliest stages of DNA fragmentation that produce the characteristic distribution of fragments sizes between $50 \mathrm{~kb}$ and $>1 \mathrm{Mb}$. Identical results were obtained when permeabilised cells were incubated with $\mathrm{Ca}^{2+}+\mathrm{Mg}^{2+}$ in the presence of chloroquine (Figure 7B lanes 1-4) indicating that this was a direct effect of chloroquine on chromatin as opposed to an effect of chloroquine on some other aspect of cellular metabolism in intact cells.

\section{Discussion}

In this manuscript we show that DNA fragmentation in apoptosis is propagated by an enzyme that introduces ssb into DNA. The three distinct fragment sizes that are generated

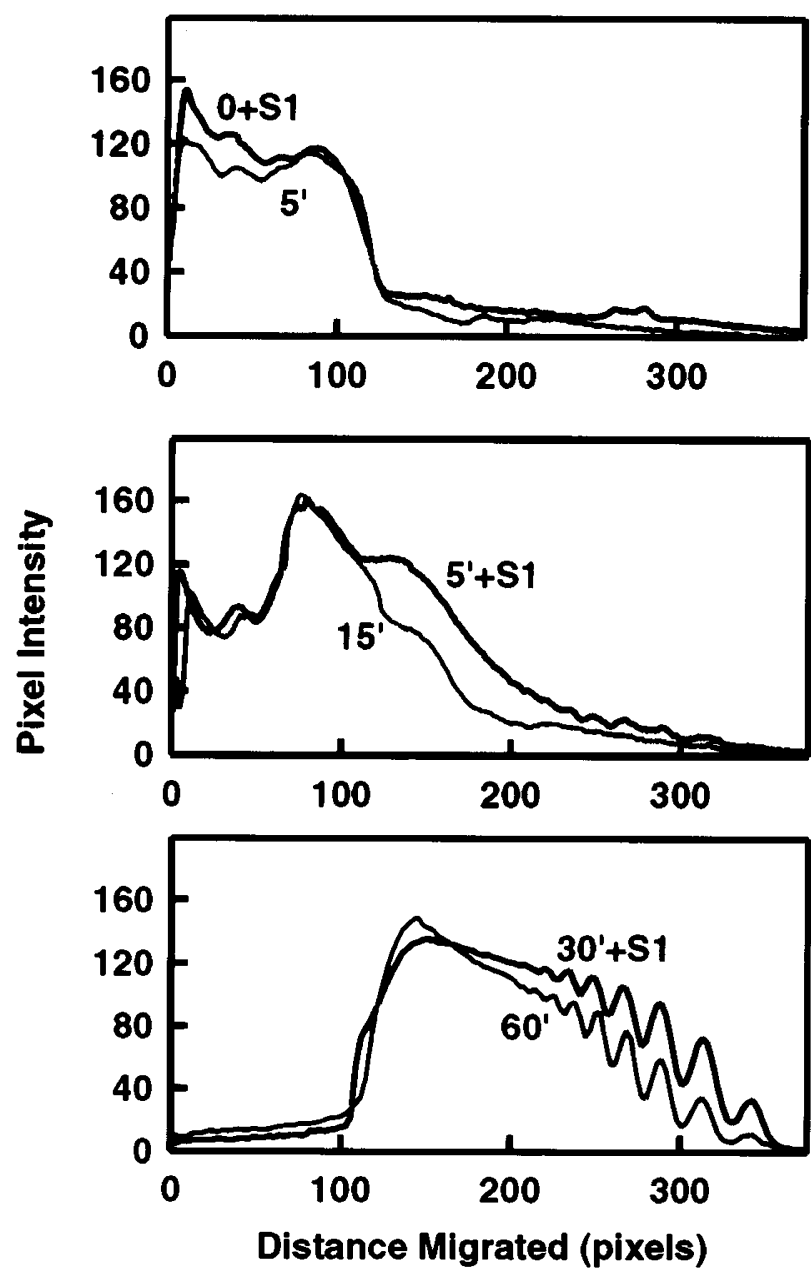

Figure 6 Comparison of the size distribution profiles from the scans in Figure $5 \mathrm{~b}$. For each panel the time of digestion with $\mathrm{Ca} / \mathrm{Mg}$ is given as well as information whether the sample was subsequently digested with $\mathrm{S} 1$ nuclease. imply the existence of three classes of sites in chromatin where ssb accumulate. Fragmentation appears to start at sites in DNA that are most likely attached to the nuclear matrix at sites of Topo II binding and where the DNA strands are known to be unpaired. In addition, a second class of sites, distinct from those at which Topo II is bound also accumulate $\mathrm{ssb}$ and the DNA is then cleaved to fragments of $50-300 \mathrm{~kb}$. Since the DNA at these sites is unpaired it is rapidly cleaved on both strands producing double-strand scissions, releasing HMW fragments. Coincident with the cleavage of these sites, ssb also begin to accumulate in the linker regions of DNA in agreement with Tomei et al (1993) and Pietsch et al (1993), but at a much earlier stage than previously determined. Thus, on denaturing gels a large number of ssb are present in HMW DNA. Eventually sufficient ssb accumulate in any given linker region to produce cleavage of both strands and oligonucleosomal fragments are released.

Although little is truly known about the highest orders of chromatin structure (see van Holde and Zlatanova (1995) for a review), it is generally accepted that interphase DNA is attached to the nuclear scaffold at a discrete number of sites known as matrix or scaffold attachment regions (MARs or SARs) thereby subdividing the polymer into topological domains (Laemmli et al, 1992). Typically, 300-2000 bp of DNA is anchored to the proteinacious scaffold at these sites creating looped-out
A

12334

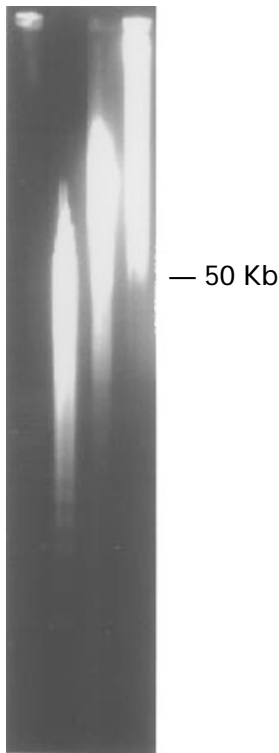

B

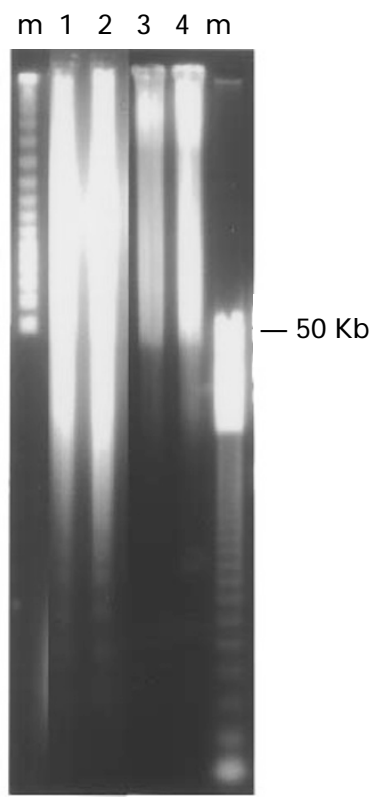

Figure 7 Effects of chloroquine diphosphate on DNA degradation in (A) embedded cells treated with dex and (B) permeabilised cells incubated with $\mathrm{Mg}^{2+}$ and $\mathrm{Ca}^{2+}$. In (A) cells were incubated for $2 \mathrm{~h}$ in the presence of dex (lane 2) or dex+1 mg/ml chloroquine (lane 3) or dex $+4 \mathrm{mg} / \mathrm{ml}$ of chloroquine (lane 4). Lane 1 shows the integrity of the DNA at 0 time. The position of the $50 \mathrm{~kb}$ DNA size marker is shown to the right. In (B) permeabilised cells were incubated for $30^{\prime}$ (lanes 1,3) or $60^{\prime}$ (lanes 2,4) with $2 \mathrm{mM} \mathrm{Mg}^{2+}$ and $1 \mathrm{mM} \mathrm{Ca}^{2+}$ in the absence (lanes 1,2) or presence (lanes 3,4 ) of $1 \mathrm{mg} / \mathrm{ml}$ chloroquine. The marker lanes $(\mathrm{m})$ are the lambda DNA ladder (left) and $123 \mathrm{bp} \mathrm{ladder} \mathrm{(right).} \mathrm{The} \mathrm{position} \mathrm{of} \mathrm{the} 50 \mathrm{~kb}$ DNA marker is indicated to the right. 
domains that can vary in size from $30 \mathrm{~kb}$ to $>1 \mathrm{Mb}$ (Laemmli et al., 1992; Glazkov, 1995; larovaia et al, 1996). Although there is no specific consensus sequence for the DNA binding at these sites it is usually AT-rich and has a propensity for being unwound or adopting unusual secondary structures that are nuclease sensitive (Probst and Herzog, 1985; Luderus et al, 1994; Szabo and Bacso, 1996). Topo II is believed to bind in these regions to control individual domain topology, but it is not clear whether it binds constitutively to all MARs or only a subset of them (larovaia et al, 1996). Given the coincidence in the distribution of fragment sizes produced by VM26-induced DNA cleavage via Topo II and cleavage of DNA by single-strand specific nucleases, such as S1 and Mung bean, we believe that the size distribution shown in Figure 4 represents the distribution of domain sizes found in thymocyte chromatin. The distribution of sizes is not uniform and distinct subsets are seen at 300 and $600 \mathrm{~kb}$ intervals reflecting additional levels of chromatin structure (Filipski et al, 1990). Any possibility that they are due to artifactual zones of compression is ruled out by the linearity of the separation under the PFGE conditions used (Figure 1). Because long stretches of the DNA in the MARs are either unwound or in secondary structures that are ss nuclease-sensitive they become the most sensitive sites for endonucleolytic attack following endonuclease activation in apoptosis or in permeabilised cells in vitro. It is not clear yet whether these regions are cleaved simply because they represent the most sensitive targets or whether the endonuclease is actually located at these sites. Since the endonucleolytic activity responsible for the initial stages of DNA degradation is more tightly-associated with chromatin than the one responsible for internucleosomal DNA cleavage (Pandey et al, 1994) it may well be bound to MARs.

During the time double-strand cleavage is occuring at the most sensitive sites, ssb begin to accumulate at a second class of sites which eventually produce cleavage of both strands further reducing the size distribution of the $50 \mathrm{~kb}-1 \mathrm{Mb}$ HMW fragments to the $50-300 \mathrm{~kb}$ size range (Figure 5 and 6 ). The latter sites have not been described before and little is known about them except that Topo II is not located there since they were not 'cut' by VM26. A similar distribution of extremely fragile sites is found in some lymphocytes (Szabo and Bacso, 1996). In our hands, the sites are cut by the ss-specific nucleases, S1 and Mung bean, and by an endogenous nuclease, activated by $\mathrm{Mg}^{2+}$ ions, in permeabilised cells. Although it is possible that the sites represent higher order structureinduced regions of nuclease accessibility it is more likely that they represent the distribution of another class of DNA sequences, distributed non-randomly throughout the genome, which are either unwound or have adopted a local nuclease-sensitive secondary structure (Henson, 1978) when organised into chromatin. However, Bal 31 nuclease which has some specificity for unusual secondary structure cannot recognise these sites. Significantly, larovaia et al (1996) have recently identified a class of SARs at which Topo II is not bound. The relationship between the latter sites and those described above remains to be identified.

Many $S 1$ nuclease-sensitive sites have accumulated in the linker regions of chromatin by the time the bulk of DNA has been cleaved to $50-300 \mathrm{~kb}$ HMW fragments (Figure $5 \mathrm{~B}$, lanes 9 and 10). These are most likely ssb (Figure 2), but changes in linker DNA topology that produce $\mathrm{S} 1$ nuclease sensitive sites may also contribute.

Double-stranded DNA fragmentation in apoptosis or permeabilised cells does not proceed past the HMW stage in the presence of protease inhibitors (Figure 3 , Weaver et al, 1994). As shown in Figure 3 there is no accumulation of ssb in the linker regions in domain-sized chromatin in the absence of proteolysis. Furthermore, experiments carried out in vitro with both isolated nuclei (Walker et al, 1995) and permeabilised thymocytes (Figure 5) have shown that the activity responsible for DNA cleavage to the HMW stage requires only $\mathrm{Mg}^{2+}$ ions whereas cleavage in the linker region requires both $\mathrm{Mg}^{2+}$ and $\mathrm{Ca}^{2+}$. Therefore, it is apparent that both proteolysis and $\mathrm{Ca}^{2+}$ are required for the formation of $\mathrm{ssb}$ in the linker regions within domains of chromatin. In addition, the data shown in Figure 7 also indicates that local unwinding of the DNA in the linker region is required to give the endonuclease access to individual strands. Thus, the proteolytic step could be required to either activate/release the endonuclease or to cleave a protein which then results in DNA bending or unwinding (Hermann et al, 1996). Since the endonuclease responsible for internucleosomal DNA fragmentation (Pandey et al, 1995) does not appear to require proteolysis for activation the former possibility is ruled out. Therefore, it is likely that proteolysis of a protein located either directly at the linker regions, or at a site in chromatin that could alter the topology of the linker regions in a whole domain of chromatin, results in local DNA unwinding thereby generating nuclease sensitive sites. In this scenario, the $\mathrm{Ca}^{2+}$-dependent step could well be either the proteolytic step or be required for the structural alteration. Changes in linker DNA topology have recently been shown to induce profound changes in chromatin structure (Widom, 1992; Yao et al, 1993; Woodcock et al, 1993; Polach and Widom, 1995; Krajewski, 1995). Since neither VM26 nor camptothecin trigger the release of small fragments there is no evidence that either Topo I or Topo II are involved in linker DNA cleavage.

This data further defines the properties of the enzyme activities required for DNA fragmentation in apoptosis. The enzyme must be active primarily on SsDNA requiring only $\mathrm{Mg}^{2+}$ for the two initial stages of HMW fragmentation and $\mathrm{Mg}^{2+}$, and possibly $\mathrm{Ca}^{2+}$, for internucleosomal DNA fragmentation. Whether this requires two distinct enzymes or one remains to be resolved. We have isolated and characterised a $\mathrm{Ca}^{2+} / \mathrm{Mg}^{2+}$-dependent endonuclease that is active against SSDNA and shown that it can catalyse internucleosomal DNA cleavage in isolated nuclei (Pandey et al, 1994). Although the proteolytic step is not yet defined it appears to lead to unwinding of the linker regions of DNA within domains rendering them nuclease sensitive. 


\section{Materials and Methods}

\section{Cells}

Thymocyte primary cultures were prepared from $200 \mathrm{~g}$ rats as described previously (Weaver et al, 1996) and cultured in the presence or absence of $10 \mu \mathrm{M} \mathrm{VM} 26,100 \mu \mathrm{M}$ camptothecin or $1 \mu \mathrm{M}$ dexamethasone (dex). Following the incubations the cells were pelleted and prepared for electrophoresis as described below. Some cells were embedded in agarose prior to incubation or permeabilisation as previously described (Weaver et al, 1996). Briefly, $3 \times 10^{7}$ cells in $0.25 \mathrm{ml}$ of medium containing $5 \%$ serum were mixed with $0.25 \mathrm{ml}$ of melted $1.5 \%$ low melting point agarose (prepared in medium without serum and held at $37^{\circ} \mathrm{C}$ ) and allowed to solidify. The embedded cells were incubated in RPMI medium containing $5 \%$ fetal bovine serum \pm dex or VM26 as described above. In some experiments incubations were carried out in the presence of $50 \mu \mathrm{M}$ dichloroisocoumarin (DCl) or $1-4 \mathrm{mg} / \mathrm{ml}$ chloroquine diphosphate.

\section{Preparation and incubation of permeabilised cells}

Thymocytes were isolated and embedded in agarose plugs as described above. In all experiments slices of $20 \mu \mathrm{l}$ in volume, containing $2 \times 10^{6}$ cells, were cut from plugs and incubated at $37^{\circ} \mathrm{C}$ in $300 \mu \mathrm{l}$ of a permeabilisation buffer consisting of $10 \mathrm{mM}$ Tris- $\mathrm{HCl}, \mathrm{pH}$ 7.0, $60 \mathrm{mM} \mathrm{KCl}, 0.1 \mathrm{mM}$ EGTA and 0.5\% Triton X100. Cations were added as described in the figure legends and incubations were carried out at $37^{\circ} \mathrm{C}$ for various times between 0 and $60^{\prime}$.

\section{Sample processing and pulsed field gel electrophoresis}

Cells not embedded in agarose plugs prior to incubation with dex or VM26 were embedded immediately following incubation as described above. $20 \mu$ l slices of plugs were deproteinised by incubation for $3 \mathrm{~h}$ at $37^{\circ} \mathrm{C}$ in $300 \mu$ of TEN buffer ( $10 \mathrm{mM}$ Tris- $\mathrm{HCl}, \mathrm{pH}$ 9.5, $25 \mathrm{mM}$ EDTA, $1 \mathrm{mM} \mathrm{EGTA}, 10 \mathrm{mM} \mathrm{NaCl}$ ) containing $4 \mu \mathrm{g}$ Proteinase $\mathrm{K}$ and $1 \% \mathrm{SDS}$. During this incubation a negligible amount of smaller DNA fragments are lost by diffusion out of the plug. The plugs were washed in TE buffer (10 mM Tris-HCl, pH 8.0, 1.0 mM EDTA) and either subject to a digestion with nucleases as described below or immediately loaded on an $0.8 \%$ agarose gel prepared in TBE buffer $(0.089 \mathrm{M}$ Tris, $0.089 \mathrm{M}$ boric acid, $25 \mathrm{mM}$ EDTA, pH 8-8.5). The wells were sealed with $1.5 \%$ (w/v) LMP agarose and PFGE was carried out using a Q-life Autobase Electrophoresis System (Kingston, ON) as described by Weaver et al $(1994,1996)$ and Walker et al (1993) using a programmed ROM card designed to separate fragments in the $200 \mathrm{bp}-1.0 \mathrm{Mbp}$ range (Romcard No. 3, $24 \mathrm{~h}$ runtime). The use of the same ROM card ensures reproducibility of resolution over many runs. Yeast chromosomes, lambda DNA ladder, low range markers (New England Biolabs, Beverly, MA), 123 bp ladder and a HindllI digest of lambda DNA (Gibco BRL Life TEchnologies, Burlington, ON) were used as size markers.

In experiments involving 2D separations the second dimension was either conventional agarose gel electrophoresis (CAGE) run as described previously (Weaver et al, 1996) or denaturing electrophoresis. For the denaturing run the gel was soaked in buffer containing $50 \mathrm{mM} \mathrm{NaOH}+1 \mathrm{mM}$ EDTA for $60^{\prime}$ and then run in the same buffer. Both second dimension runs were carried out at $150 \mathrm{v}$ for $2.5 \mathrm{~h}$ with the buffer being recirculated and cooled to $5^{\circ} \mathrm{C}$.

All the gels were stained with ethidium bromide, placed on a transilluminator and either photographed onto Polaroid MP4 film or the image captured using an Ultra-Lum CCD camera imaging data acquisition system.

\section{Digestion of embedded DNA with nucleases}

Embedded, deproteinised DNA was incubated with either S1 nuclease, Mung bean nuclease or Bal 31 as described in the figure legends. For the $\mathrm{S} 1$ nuclease digestions plug slices were incubated in a buffer containing $30 \mathrm{mM}$ Acetate buffer, $\mathrm{pH} 4.6,100 \mathrm{mM} \mathrm{NaCl}$, $0.5 \mathrm{mM}$ zinc chloride and $450 \mathrm{U}$ of enzyme. Mung bean nuclease digestions were carried out in $30 \mathrm{mM}$ acetate buffer, $\mathrm{pH}$ 4.6, containing $50 \mathrm{mM} \mathrm{NaCl}, 1 \mathrm{mM}$ zinc chloride, $0.01 \%$ Triton $\mathrm{X} 100$ and $80 \mathrm{U}$ of enzyme. Bal 31 digestions were carried out in $20 \mathrm{mM}$ Tris- $\mathrm{HCl}$, pH 8.0 , $200 \mathrm{mM} \mathrm{NaCl}, 12 \mathrm{mM} \mathrm{CaCl}_{2}, 12 \mathrm{mM} \mathrm{MgCl}_{2}$ and $5 \mathrm{U}$ of enzyme. All the incubations were carried out for $60^{\prime}$ unless otherwise stated.

\section{Data analysis}

The digitised images were subsequently used to generate scans of pixel intensity vs. distance of migration for each lane. Standard curves were generated by regression analysis of the positions of overlapping DNA size markers. The total amount of fragmented DNA in each sample was calculated by integrating the pixel intensity of each scan after subtracting the zero time control from each timepoint.

\section{References}

Appleby DW and Modak SP (1977) DNa degradation in terminally differentiating lens fiber cells from chick embryos. Proc. Natl. Acad. Sci. USA 74: 5579-5583

Arruti C, Chaudun E, De Maria A, Courtois Y and Counis MF (1995) Characterisation of eye-lens DNases: Long term persistence of activity in post apoptotic lens fibre cells. Cell Death Differ. 2: 47-56

Filipski J, Leblanc J, Youdale T, Sikorska M and Walker PR (1990) Periodicity of DNA folding in higher order chromatin. EMBO J 9: 1319-1327

Glazkov MV (1995) Loop-domain gene structure in eukaryotic chromosomes. Mol Biol-Engl Tr 29: $561-571$

Gromkowski SH, Brown TC, Cerutti PA and Cerottini J-C (1986) DNA of Human Raji Target Cells is Damaged upon Lymphocyte-mediated lysis. J Immunol 136: $752-756$

Gromova II, Nielsen OF and Razin SV (1995a) Long-range fragmentation of the eukaryotic genome by exogenous and endogenous nucleases proceeds in a specific fashion via preferential DNA cleavage at matrix attachment sites. J Biol Chem 270: $18685-18690$

Gromova II, Thomsen B and Razin SV (1995b) Different topoisomerase II antitumor drugs direct similar specific long-range fragmentation of an amplified c-MYC gene locus in living cells and in high-salt extracted nuclei. Proc Natl Acad Sci USA 92: $102-106$

Henson P (1978) The presence of single-stranded regions in mammalian DNA. J Mol Biol 119: 487-506

Herrmann M, Voll R, Woith W, Hagenhofer M, Lorenz H-M, Manger B and Kalden JR (1996) Small DNA fragments isolated from human T-cell clones are enriched in sequences involved in DNA bending. Cell Death Differ. 3: 391 - 395

larovaia O, Hancock R, Lagarkova M, Miassod R and Razin SV (1996) Mapping of genomic DNA loop organization in a 500-kilobase region of the Drosophila $\mathrm{X}$ chromosome by the topoisomerase II-mediated DNA loop excision protocol. Mol Cell Biol. 16: 302-308

Krajewski WA (1995) Alterations in the internucleosomal DNA helical twist in chromatin of human erythroleukemia cells in vivo influences the chromatin higher-order folding. FEBS Lett. 361: 149-152

Laemmli UK, Kas E, Polijak E and Adachi Y (1992) Scaffold associated regions: cisacting determinants of chromatin structural loops and functional domains. Curr. Opin. Genet. Dev. 2: 275-285

Lagarkova MA, larovaia OV and Razin SV (1995) Large-scale fragmentation of mammalian DNA in the course of apoptosis proceeds via excision of chromosomal DNA loops and their oligomers. J Biol Chem. 270: 20239-20241 
Luderus MEE, Denblaauwen JL, Desmit OJB, Compton DA and Vandriel R (1994) Binding of matrix attachment regions to lamin polymers involves single-stranded regions and the minor groove. Mol Cell Biol. 14: 6297-6305

Muel AS, Chaudun E, Courtois Y, Modak SP and Counis MF (1986) Nuclear Endogenous Ca2+-dependent Endodeoxyribonuclease in Differentiating Chick Embryonic Lens Fibers. J. Cell Physiol. 127: 167-174

Pandey S, WalkerPR and Sikorska M(1994) Separate pools of endonucleaseactivity are responsible for internucleosomal and high molecular mass DNA fragmentation during apoptosis. Biochem. Cell Biol. 72: 625-629

Pietsch MC, Muller C and Tschopp J (1993) DNA fragmentation during apoptosis is caused by frequent single-strand cuts. Nucleic Acids Res. 21: 4206-4209

Polach KJ and Widom J (1995) Mechanism of protein access to specific DNA sequences in chromatin: A dynamic equilibrium model for gene regulation. J. Mol. Biol. 254: $130-149$

Probst $\mathrm{H}$ and Herzog R (1985) DNA regions associated with the nuclear matrix of Ehrlich ascites cells expose single-stranded sites after deproteinization. Eur. J. Biochem. 146: 167-171

Ribeiro EA, Larcom LL and Miller DP (1989) Quantitative Flourescence of DNAIntercalated Ethidium Bromide on Agarose Gels. Anal. Biochem. 181: 197-208

Sun XM and Cohen GM. (1994) Mg2+-dependent Cleavage of DNA into Kilobase Pair Fragments is Responsible for the Initial Degradation of DNA in Apoptosis. J. Biol. Chem. 269: 14857-14860

Szabo G Jr and Bacso Z (1996) Chromatin isolated from viable human PBLs contains DNA fragmented to $>50 \mathrm{~kb}$. Cell Death Differ. 3: 237-241

Tomei LD, Shapiro JP and Cope FO (1993) Apoptosis in C3H/10T1/2 Mouse Embryonic Cells - Evidence for Internucleosomal DNA Modification in the Absence of Double-Strand Cleavage. Proc. Natl. Acad. Sci. USA 90: 853-857

Ucker DS, Obermiller PS, Eckhart W, Apgar JR, Berger NA and Meyers J (1992) Genome digestion is a dispensable consequence of physiological cell death mediated by cytotoxic t lymphocytes. Mol. Cell Biol. 12: 3060-3069

van Holde K and Zlatanova J (1995) Chromatin higher order structure: Chasing a mirage? J Biol. Chem. 270: 8373-8376
Walker PR, Smith C, Youdale T, Leblanc J, Whitfield JF and Sikorska M (1991) Topoisomerase II-reactive chemotherapeutic drugs induce apoptosis in immature thymocytes. Cancer Res. 51: 1078-1085

Walker PR, Kokileva L, Leblanc J and Sikorska M(1993) Detection of the initial stages of DNA fragmentation in apoptosis. Biotechniques. 15: 1032-1041

Walker PR, Pandey S and Sikorska M (1995) Degradation of Chromatin in Apoptosis. Cell Death Differ. 2: 97-104

WalkerPR and Sikorska M (1994) Endonuclease activities, chromatin structure, and DNA degradation in apoptosis -Review. Biochem. Cell Biol. 72: 615-623

Weaver VM, Lach B, Walker PR and Sikorska M (1994) Role of proteolysis in apoptosis: involvement of serine proteases in internucleosomal DNA fragmentation in immature thymocytes. Biochem. Cell Biol. 71: 488-500

Weaver VM, Carson CE, Walker PR, Chaly N, Lach B, Raymond Y and Sikorska M (1996) Degradation of nuclear matrix and DNA cleavage in apoptotic thymocytes. J. Cell Sci. 109: 45-56

Widom J (1992) A relationship between the helical twist of DNA and the ordered positioning of nucleosomes in all eukaryotic cells. Proc. Natl. Acad. Sci. USA 89: $1095-1099$

WoodcockCL, Grigoryev SA, Horowitz RA and WhitakerN (1993)A chromatin folding model that incorporates linker variability generates fibers resembling the native structures. Proc. Natl. Acad. Sci. USA 90: 9021-9025

Wyllie AH (1980) Glucocorticoid-induced thymocyte apoptosis is associated with endogenous endonuclease activation. Nature 284: 555-556

Yao J, Lowary PT and Widom J (1993) Twist constraints on linker DNA in the 30-nm chromatin fiber: Implications for nucleosome phasing. Proc. Natl. Acad. Sci. USA 90: $9364-9368$

Zhivotovsky B, Cedervall B, Jiang S, Nicotera P and Orrenius S (1994) Involvement of $\mathrm{Ca} 2+$ in the formation of high molecular weight DNA fragments in thymocyte apoptosis. Biochem. Biophys. Res. Commun. 202: 120-127. 